\title{
Flax Seeds In Prostate Cancer A Case report- self experienced.
}

\author{
DR. Harbans Singh M.S, Phd,(Surgery) \\ Retd. Principal and Head Department of surgery, Govt. medical College Kota(Raj).
}

\begin{abstract}
Background:- High risk advanced prostate cancer are beyond the scope of radical treatments more so they are associated with significant morbidity (1). Addition of flaxseeds to diet are likely to provide relief in the management of prostate cancer as experienced by Author.

Brief History:- I am confirmed case of high risk prostate cancer diagnosed on 12.3.12 Biopsy Lal path no.127544646 prostate core Biopsy adenocarcinoma (Acinor,NOS) Glesson score- $4+4=8$, tumor invades $70 \%$ of core volume, perineural invasion seen. USG abdomen: prostate $42 \mathrm{~g}$ heterogenous with breach in right lobe, Pelvis and abdominal node-enlarged largest $3 \mathrm{~cm}$. All Routine investigation within normal range, PSA-246, Bone scan a few mets (right pelvic bone and two ribs). Personal data thin, tall(5'9"), Weight 52kg. , BP122/80, vegetarian no addiction.

Treatment:- On 14.3.12 bilateral orchidectomy Followed by Bicalutamide and honovan.
\end{abstract}

\section{Response:-}

PSA=- subsequent readings(2012)- April<4, June-2.1,

September-34,-december 57(rising trend).

Left supraclavicular nodes also started enlarging as I noticed in September 2012.

On December 15,2012- I stopped all treatment as PSA was rising. Rising PSA was an Indication that therapy is not working. I searched for alternative therapy and found that flaxseeds supplementation reduces prostate cancer proliferation.(2)

From 15december 2012 after all I resored to flaxseeds therapy (i.e. 30g Powdered flaxseeds taken with curd per day Or sprinkled over cooked vegetables). There was dramatic response that by feburary 2013PSA was below one. Scince then it is below one i.e. on 11.3.17 PSA $<0.07$.

DIET:-

I changed my diet, No animal or processed food no beverages Added fresh fruits, Lot of salad.

\section{Observation}

Subjective: weight loss $2 \mathrm{~kg}$, skin papery, thin (? Loss of subcutaneous fat), Loss of body hair, Gynecomastia , abdominal girth increased by $2.5 \mathrm{~cm}$, urinary stream improved feeling of wellbeing, working normally.

Objective:- Since feburary 2013 PSA below one(0.07) also same on 11.3.2017.

USG-prostate size reduced to $18 \mathrm{~g}$, abdmonial and supracalvicular nodes disappeared, bone scan mets stabilized. Since then subjective and objective observational data are same.

Flax seeds are richest source of plant based

\section{Discussion}

Omega-3 fatty acids called Alpha- Linolemic Acid(ALA) . secondly flaxseeds are high in lignan antioxidants also commonly referred as phytoestrogen.

Omega 3 fatty acids reduce LDL and increase HDL thus clears vessels of cholesterol deposits. It is considered as healthy fat and should be include in balanced diet. After ingestion flaxseeds are metabolized and converted into enterolignans, enterolacton and enterodiol via ae robic instestinal flora(3). Entaerolactone a major metabolite of flax seeds suppresses proliferation and migration of prostrate cancer cells. The lignans of flaxseeds have properties to reduce blood supply and induce aptosis and modulate immune system $(4,5)$.

Clinicial studies by Azrad et al 2013 (6)stated that flaxseeds derived enterolactone is inversely associated with tumore cell proliferation in men with localized prostate cancer. Tinakaczor (2014) (7). extracted data from above study and find that flaxseeds can reduce aggressiveness of an already existing tumor of prostate.

Diet also plays role $\mathrm{m}$ management of prostate cancer low fat diet i.e. $20 \%$ less fat diet reduce tumor proliferation (8), Low fat reduces weight and weight loss may reduce prostate aggressiveness thus taken together i.e. flaxseeds and low fat diet in combination might often benefits to some men with cancer prostate. Two vitrostudies also support that enterolactone merabolite of flaxseeds reduce prostate cancer development and proliferation $(9,10)$. 


\section{Conclusion}

Flaxseeds is safe, less expensive easy to obatine, does not interfare with existing treatment. Itcan be used in routine diet no contra-indication, no adverse reaction. The present finding are encouraging and may play role in Indian senerio as many Indian patient are poor and radical treatments are Costly. Author has no hestation in recommending this to all patients of prostate cancer at are stages. Further large studies are needed to decide, clinical decision making.

\section{References}

[1]. TAIMUR SHAH , Manit Arya, Jhon D Kelly, Modern Prostate cancer management, Recent Advances in Surgery Vd. 37,2015 , 131,144 .

[2]. Demark-wahne fried W,Polasik T J, Geroge S L, etal

[3]. Flaxseeds supplementation (Not dietry fat restriction) reduse prostate cancer proliferation rates in men pre surgery. Cancer epidemiol, Biomarkes Prev.2008;17(12):3577-3587.

[4]. Borrielo SP. Setchell KD Axelson, M Lawson A.M. Production and metabolism of lignans by the human fecal flora. J Appl Bacteriol. 1985;58;37-43.

[5]. Corsini E; Dell Agli M; Facchi A etal. Enterodiol and enterolatone modulate the immumme response by acting on nuclear factorkappa B(NF-Kappa B) signalivg. J.Agric Food chem. .2011;58:6678-6684.

[6]. Chen LH; Fang J, Li H et al: Enterolactone induces aptosis in human prostate carcinoma LNC ap Cell via mitochandricl mediated caspase dependent pathway Mol Cancer there 2007 ; 6 (9): 2581-2590.

[7]. Azrad M, Vollimer RT, MaddenJ.etal: Flaxseeds-dirved erolactone is inversely associated with tumor cells proliferation in men with localized prostate cancer: J.Med Food $2013 ; 16$ (4) :357-003360.

[8]. Tina Kaczor Flaxseeds reduce prostate cancer aggressiveness. Natural Medicine Journal February 2014, Volume 6,issue 22.

[9]. Heymach. JV,Shack lefordTJ. Tran HT.etal.Effect of low fat diet on plasma level of NF(Kappa) B-Regulated inflammatory cytokines and angiogenic factors in men with prostate cancer. Cancer Prev Res.2011;4:1590-1598.

[10]. McCAnn.MJ,Gill,CL,Linton T. etal: Enterolactone restricts the proliferation of the LNcap human prostate cancer cellline in vitro Mol Nutor Food Res.2008;52(5):567-580.

[11]. McCann.MJ,Rowland IR,Roy Nc. Anti-proliferative effects of Physiological Concentrations of enterolactone in models of prostate tumourigenesis. Mol-Nutr Food Res. 2013 Feburary ; 57 (2):212-24. 